\title{
An Incessant Need for Review Articles
}

\author{
Subhash C Parija ${ }^{1}$, Shanmuganathan Padmavathi ${ }^{2}$
}

Annals of SBV (2019): 10.5005/jp-journals-10085-8105

It is well proved that the highest and strongest evidence of research is achieved by systematic reviews and meta-analyses. In this era of evidence-based practice (EBP), every healthcare professional relies on such a highest order of evidence. Medical review articles written before the era of EBP were conventionally unsystematic and lacked application of statistical methods to arrive at a definitive conclusion on a controversial subject. By means of a good, extensive systematic review on a contemporary interesting, or even a controversial topic, we can considerably enrich both the scientific community and the public.

The classical and most common form of review is the narrative review through which an author can offer to the readers adequate information and critiques of many research works based on his/ her interpretation of the data. The systematic review is at the peak level of hierarchy of evidence in healthcare. It is a methodological approach to gather, appraise, and compile the available data on a predefined research question. There are nearly 14 different types of review articles mentioned in the literature. ${ }^{1}$ Each one is unique and has its own strengths and weaknesses. Through different types of review articles, one can either enlighten the research community on a new idea or find a solution to a controversial problem.

A well-written and an effective review can offer the readers with rich information on various aspects of a topic, provide better understanding of the same, pose challenges to existing opinions, identify existing gaps, and synthesize new ideas for future research. Further, a review can be helpful in summarizing the pros and cons of the issues and at times in decision-making on a specific research question or a controversial topic. ${ }^{2}$ Every review cannot cover all these aspects but most of the information can be obtained through an effective review article. A review written with extensive analysis and compilation of findings of many research works by a well-experienced researcher can provide a fruitful and meaningful
${ }^{1}$ Sri Balaji Vidyapeeth, Puducherry, India

${ }^{2}$ Department of Pharmacology, Mahatma Gandhi Medical College and Research Institute, Sri Balaji Vidyapeeth, Puducherry, India

Corresponding Author: Shanmuganathan Padmavathi, Department of Pharmacology, Mahatma Gandhi Medical College and Research Institute, Sri Balaji Vidyapeeth, Puducherry, India, Phone: +91 9842030490, e-mail: padmavathis@mgmcri.ac.in

How to cite this article: Parija SC, Padmavathi S. An Incessant Need for Review Articles. Ann SBV 2019;8(1):1.

Source of support: Nil

Conflict of interest: None

outcome. Such a review can generate new insights in the topic in particular and area of knowledge in general. ${ }^{3}$

The present issue of Annals of SBV features a few but diverse articles with different flavor of expressions. This is just a beginning. We can expect a stream of review articles and new columns to be added in the future to make this journal a unique journal among the ocean of scientific literature.

\section{References}

1. Grant MJ, Booth A. A typology of reviews: an analysis of 14 review types and associated methodologies. Health Info Libr J 2009;26(2): 91-108. DOI: 10.1111/j.1471-1842.2009.00848.x.

2. Palmatier RW, Houston MB, Hulland J. Review articles: purpose, process, and structure. J Acad Mark Sci 2018;46:1-5. DOI: 10.1007/ s11747-017-0563-4.

3. Suter GW. Review Papers are Important and Worth Writing. Environ Toxicol Chem 2013;32(9):1929-1930. DOI: 10.1002/etc.2316.

() The Author(s). 2019 Open Access This article is distributed under the terms of the Creative Commons Attribution 4.0 International License (https://creativecommons. org/licenses/by-nc/4.0/), which permits unrestricted use, distribution, and non-commercial reproduction in any medium, provided you give appropriate credit to the original author(s) and the source, provide a link to the Creative Commons license, and indicate if changes were made. The Creative Commons Public Domain Dedication waiver (http://creativecommons.org/publicdomain/zero/1.0/) applies to the data made available in this article, unless otherwise stated. 